\title{
Analisis Efektivitas Kelembagaan Pengelolaan Hutan Bersama Masyarakat (PHBM) di KPH Bandung Utara Jawa Barat
}

\author{
Bahruzin $^{1)}$, Aceng Hidayat ${ }^{2)}$, Eka Intan Kumala Putri ${ }^{3)}$
}

INFO NASKAH :

Proses Naskah:

Diterima 13 Januari 2014

Diterima hasil revisi 2 Maret 2014

Diterima untuk terbit 5 April 2014

Terbit April 2014

Keywords :

PHBM

Instutional effectiviness

IPA (Importance of Performance

Analysis)

\begin{abstract}
Community-based forest management (CBFM) was aimed to achieve the sustainability of forest functions and to omptimize its benefits. CBFM around the Forest Lap Area in North Bandung is a joint forest management between Perum Perhutani and forest villagers. The purposes of this study were; (1) to analyse the processes and stakeholders of CBFM, (2) to analyse the institution effectiveness of CBFM, (3) to analyse the result of the CBFM implementation The approach of this research was the stakeholder analysis and IPA (importance of Performance
\end{abstract}

Analysis). The result of stakeholder mapping showed that Perum Perhutani and LMDH had the role in the implementation of CBFM system. The results of the economic impact of CBFM calculations indicated that the system could increase the income of MDH. This was indicated by the change in the average income of farmers by $63 \%$. The result of IPA could be seen from the mapping of availability level of forest resources and forest resource need for the community included in B quadran in which it had a high level of availability and interest.

\section{PENDAHULUAN}

Hutan merupakan salah satu sumberdaya yang bersifat common-pool resources (CPRs) yang sering menimbulkan konflik pemanfaatan (Schlager dan Ostrom, 2005). Ostrom (2003) menjelaskan bahwa pengelolaan hutan yang dilaksanakan oleh negara banyak yang berhasil akan tetapi menghadapi banyak tantang konflik dengan masyarakat dan membutuhkan biaya yang cukup tinggi. Hak properti bukan bermakna sempit sebagai hak kepemilikan (ownership) saja, yang sering sekali menjadi isu yang sensitif ketika kita

Bahruzin.

Anggota Dewan Ketahan Pangan Propinsi Jawa Barat

e-mail: bahruzinmuntako@gmail.com

Aceng Hidayat

Departemen Ekonomi Sumberdaya dan Lingkungan, Institut Pertanian Bogor

e-mail: a.hidayat@gmail.com

Eka Intan Kumala Putri

Departemen Ekonomi Sumberdaya dan Lingkungan, Insititut Pertanian Bogor

e-mail: ekaintanputri@yahoo.com 
membicarakannya dalam konteks pengelolaan sumberdaya hutan di Indonesia. Hak properti mencakup pengertian yang luas dan tidak sekedar hak, tetapi juga kewajiban dan aturan (Ostrom, 2003). Untuk mendapat legitimasi, klaim atas sumberdaya tersebut harus diakui secara kolektif oleh masyarakat. Konflik akan muncul ketika terdapat klaim yang berbeda atas sumberdaya tertentu yang ditopang oleh sumber legitimasi yang berbeda. Pengaruh masyarakat desa hutan (MDH) terhadap aspek sosial dan ekonomi masyarakat Jawa Barat cukup signifikan. Hal itu disebabkan oleh jumlah desa hutan di Jawa Barat meliputi seperempat dari jumlah desa (1.370 desa) dengan jumlah penduduk mencapai 7.826.914 jiwa. Menanggapi keadaan tersebut, Pemerintah Provinsi Jawa Barat menerbitkan Peraturan Daerah (Perda) No. 10 Tahun 2011 Tentang Perlindungan dan Pemberdayaan Masyarakat Desa Hutan. Penerbitan peraturan tersebut diharapkan menjadi solusi terhadap hambatan akses masyarakat terhadap sumberdaya hutan. Pemanfaatan hutan oleh masyarakat dimaksudkan untuk mengoptimalkan fungsi hutan melalui lembaga pengelolaan dan peningkatan kesejahteraan masyarakat desa hutan secara berkeadilan, dengan tetap menjaga kelestarian hutan (Heryawan 2011). Keberadaan PHBM di KPH Bandung Utara merupakan solusi terhadap berkurangnya akses masyarakat terhadap hutan sebagai konsekuensi terbitnya SK Menteri Kehutanan No. 195 tahun 2003 tentang Re-scoring Kawasan Hutan. Awalnya 70\% hutan di KPH Bandung Utara merupakan hutan produksi, tetapi berdasarkan re-scoring tersebut hutan produksi menjadi 30\% dan hutan lindung 70\% (Perum Perhutani Unit III 2012).

Penelitian ini dilakukan untuk mengetahui permasalahan dan peran kelembagaan PHBM dalam peningkatan kesejahteraan masyarakat desa hutan dan pelestarian hutan (ekologi) di KPH Bandung Utara. Rumusan masalah dalam penelitian ini adalah: (1) Bagaimana proses terbentuknya kelembagaan PHBM dan siapa sajakah stakeholder yang terlibat? (2) Bagaimana efektivitas kelembagaan PHBM dalam mencapai tujuannya? (3) Berapa besar kontribusi PHBM terhadap pendapatan rumah tangga petani dan Berapa besar dampak keberadaan PHBM terhadap ekologi hutan? Penelitian ini memiliki tujuan umum untuk menganalisis efektivitas kebijakan PHBM di hutan lindung KPH Bandung utara. Adapun secara khusus penelitian ini bertujuan untuk: (1) Menganalisis proses terbentuknya kelembagaan PHBM dan stakeholder yang terlibat, (2) Menganalisis efektivitas kelembagaan PHBM dalam mencapai tujuannya, (3) Menganalisis kontribusi PHBM terhadap pendapatan rumah tangga petani anggota PHBM, dan (4) Menganalisis dampak PHBM terhadap ekologi hutan. Alur kerangka penelitian terlampir pada lampiran 1.

\section{METODE PENELITIAN}

\section{Lokasi dan Waktu Penelitian}

Penelitian dilakukan di empat LMDH KPH Bandung Utara, yaitu LMDH Kertawangi, LMDH Cikole dan LMDH Cihideung yang berada pada KBPH/RPH Lembang/Cisarua dan LMDH Cipada yang berada pada KBPH/RPH Padalarang/ Burangrang Selatan. LMDH Cipada dan Kertawangi berada paling dekat dengan hutan, sementara LMDH Cihideung dan Cikole berada paling jauh dari hutan. Pengambilan data dilaksanakan pada bulan Agustus Oktober 2013. Penelitian secara keseluruhan dilaksanakan pada bulan Mei 2013 - Maret 2014. Peta lokasi penelitian terlampir pada Lampiran 2.

\section{Jenis dan Sumber Data}

Jenis data yang akan dikumpulkan dalam penelitian ini terdiri dari dua jenis data yaitu data primer dan data sekunder (Sugiyono 2008).

1. Data primer, yakni data yang diperoleh secara langsung di lapangan untuk mengetahui proses pembentukan kelembagaan PHBM, efektivitas kelembagaan PHBM dan dampaknya terhadap ekonomi dan ekologi. Data tersebut diperoleh melalui kuesioner, wawancara mendalam (depth interview) dengan informan kunci, Focus Group Discussion 
(FGD) melalui metode Participatory Rural Appraisal (PRA) dan pengamatan lapangan (observasi). Adapun data primer dalam penelitian ini adalah data responden (jenis kelamin, usia, pendidikan, pekerjaan, pendapatan, dan lama menjadi anggota PHBM), data tingkat kepentingan dan pengaruh stakeholder, data pendapatan rumah tangga petani masyarakat desa hutan, dan data persepsi kondisi ekologi.

2. Data sekunder diperoleh dari Perum Perhutani, LMDH dan dokumen lain terkait masalah penelitian. Adapun data sekunder dalam penelitian ini adalah data laporan kegiatan PHBM, dokumen perjanjian kerjasama Perhutani dengan LMDH, peta wilayah KPH Bandung Utara, peraturan perundangan terkait sistem PHBM, dan laporan tahunan LMDH.

Sumber data dalam penelitian ini terdiri atas informan dan responden. Responden untuk stakeholder berjumlah 15 responden sebagai key person, sedangkan responden untuk analisis pendapatan rumah tangga adalah masyarakat desa hutan yang tinggal terdekat dengan kawasan hutan KPH Bandung Utara berjumlah 420 orang petani. Masing-masing LMDH diambil 100 orang sebagai responden penelitian, kecuali LMDH Kertawangi berjumlah 120 orang. Perbedaan tersebut dikarenakan jumlah anggota di LMDH Kertawangi lebih banyak jika dibandingkan dengan ketiga LMDH lainnya. Jumlah sampel untuk rumah tangga pada masing-masing LMDH dihitung berdasarkan rumus ukuran sampel sebagai berikut:

Keterangan :

$$
\mathrm{n}=\frac{N}{1+N e^{2}}
$$

$\mathrm{n}$ = responden

$\mathrm{N}=$ populasi

e $=$ koefisien kesalahan

(Husen, 1999)

Berdasarkan rumus pengambilan sampel menurut Husen (1999) didapat jumlah sampel bagi LMDH Cipada sebanyak 72 responden, Kertawangi 80 responden, Cihideung 78 responden dan Cikole 75 responden. Jumlah sampel dari populasi keseluruahan 1313 orang sebanyak 93 responden. Namun demikian untuk keperluan validasi data (kuisioner) masing-masing LMDH diambil 100 orang sebagai responden penelitian, kecuali LMDH Kertawangi berjumlah 120 orang. Perbedaan tersebut dikarenakan jumlah anggota di LMDH Kertawangi lebih banyak jika dibandingkan dengan ketiga LMDH lainnya.

\section{Metode Pengambilan Sampel}

Metode penentuan LMDH dilakukan secara purposive sampling berdasarkan pertimbangan kedekatan lokasi LMDH terhadap hutan dimana merupakan tempat berdomisilinya masyarakat desa hutan yang aktif dalam sistem PHBM. Secara geografis LMDH yang dipilih adalah LMDH yang terdekat dan terjauh dengan hutan. Teknik pengambilan sampel terhadap responden stakeholder (key person) menggunakan metode snowball sampling, sedangkan untuk responden rumah tangga petani dilakukan dengan menggunakan metode random sampling.

\section{Metode Pengolahan dan Analisis Data}

Analisis yang digunakan dalam penelitian ini menggunakan pendekatan deskriptif kualitatif yang digunakan secara dominan dan ditunjang dengan metode kuantitatif (Creswell 2003). Metode kualitatif melalui analisis deskriptif kualitatif digunakan untuk memperoleh informasi dari informan kunci (key person) tentang proses terbentuknya kelembagaan PHBM dan efektivitas kelembagaan PHBM yang dilakukan Perum Perhutani bersama masyarakat. Metode kuantitatif digunakan untuk mengetahui pendapatan dan penilaian masyarakat yang ikut dalam program PHBM ditinjau dari aspek kelembagaan, ekonomi dan ekologi. 


\section{Analisis Stakeholder dalam PHBM}

Analisis ini dilakukan untuk mengidentifikasi stakeholder beserta pengaruh dan kepentingannya pada kelembagaan PHBM. Stakeholder dalam penelitian ini akan dibagi berdasarkan pengaruh dan kepentingan serta perannya secara langsung atau tidak dalam kelembagaan PHBM. Pengolahan data dalam penelitian digunakan metode analisis stakeholder menggunakan actor grid.

\section{Analisis Efektivitas Kelembagaan PHBM}

Analisis efektivitas kelembagaan meliputi dua bagian, yaitu: analisis prasyarat kelembagaan dan analisis kinerja kelembagaan. Analisis efektivitas kelembagaan ditujukan untuk melihat apakah kelembagaan tersebut berjalan efektif atau tidak? Adapun indikator efektivitas kelembagaan, terdapat 2 komponen:

- Struktur organisasi, yang akan menjelaskan mengenai hubungan LMDH secara internal dan eksternal ( masyarakat, Perhutani dan pemerintahan LMDH).

- Infrastruktur organisasi, yang akan menjelaskan mengenai aturan main, program kerja, reward dan punishment, akuntabilitas organisasi, dan lain-lain.

\section{Analisis Dampak Ekonomi dan Ekologi}

Dampak ekonomi yang dimaksud pada penelitian ini adalah kontribusi kegiatan PHBM terhadap pendapatan rumah tangga masyarakat desa hutan. Untuk mengetahui kontribusi PHBM terhadap pendapatan rumah tangga masyarakat desa hutan dihitung dengan menggunakan rumus sebagai berikut :

$$
\text { Persentasi Kontribusi PHBM }=\frac{\text { Penerimaan PHEM }}{\text { Total Pendapatan }} \times 100 \%
$$

Analisis terhadap dampak ekologi dilakukan dengan menggunakan metode presepsi masyarakat dan dianalisis dengan metode IPA (Importance Performance Analysis). Metode Importance Performance Analysis (IPA) diperkenalkan oleh Martilla dan James pada tahun 1977 untuk mengukur hubungan antara prioritas peningkatan kualitas produk/jasa yang dikenal pula sebagai quadrant analysis. Metode Importance-Performance Analysis (IPA) terdiri atas dua kemponen yaitu, analisis kuadran dan analisis kesenjangan (gap). Langkah pertama untuk analisis kuadran adalah menghitung rata-rata penilaian kepentingan dan kinerja setiap produk layanan,

$$
\overline{X_{l}}=\frac{\sum_{i=l}^{k} X i}{n} \quad \overline{Y_{l}}=\frac{\sum_{\mathrm{i}=l}^{k} Y_{l}}{n}
$$

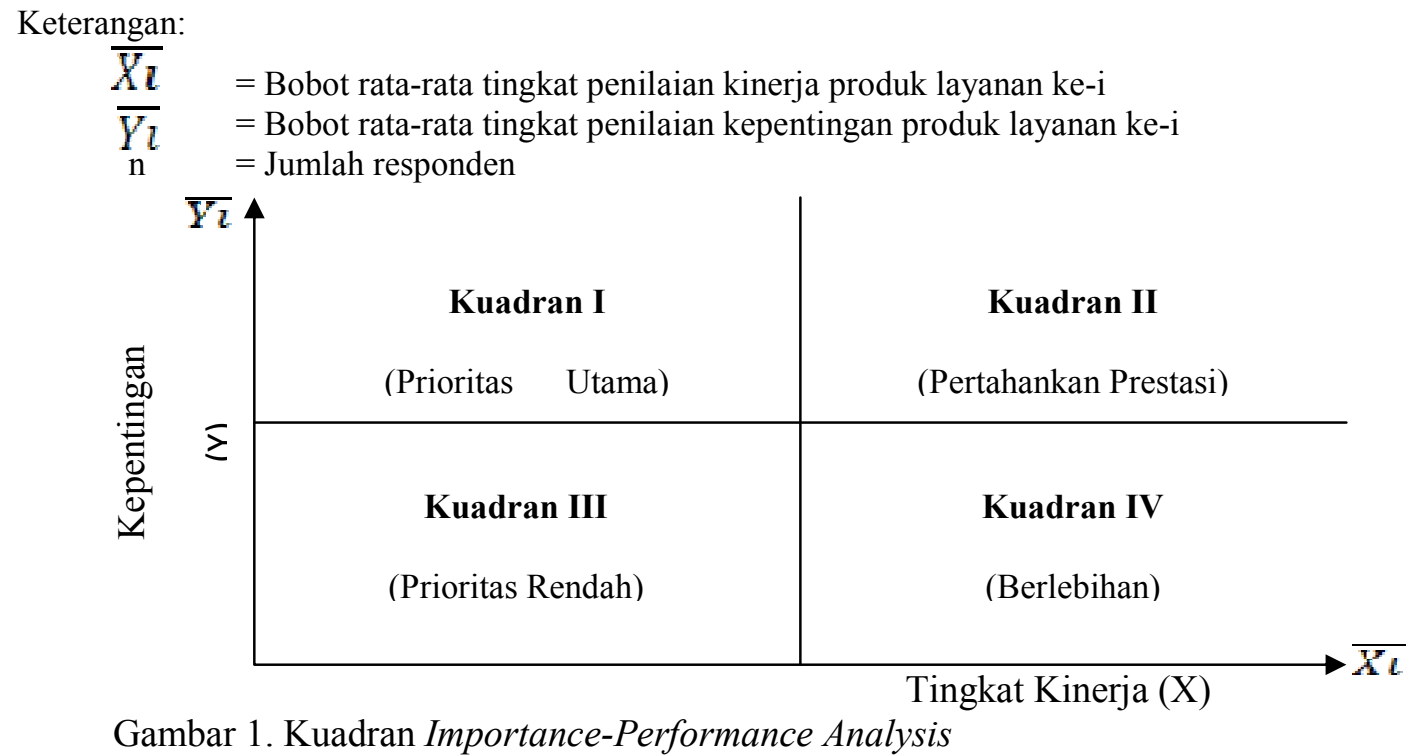

Bahruzin, A. Hidayat, E. Intan Kumala Putri / JAREE 1 (2014) 1-11 
Selanjutnya nilai rata-rata kepentingan $\left(\overline{Y_{l}}\right)$ dan nilai rata-rata kinerja $\left(\overline{X_{\boldsymbol{l}}}\right)$ di petakan kedalam grafik kartesius yang dibagi kedalam empat kuadaran (Gambar 1)

\section{HASIL DAN PEMBAHASAN ANALISIS EFEKTIVITAS KELEMBAGAAN PHBM}

\section{Stakeholder dalam Kelembagaan PHBM}

Aktor-aktor yang terlibat dalam sistem PHBM di KPH Bandung Utara secara umum dapat dikelompokkan dalam tiga kelompok aktor, yaitu Perum Perhutani Unit III, Lembaga Masyarakat Desa Hutan (LMDH) dan stakeholder lainnya. Identifikasi stakeholder dalam Pengelolaan Hutan Bersama Masyarakat (PHBM) dapat dilihat pada Tabel 1.

Tabel 1 Identifikasi nilai kepentingan dan pengaruh masing-masing stakeholder pada sistem PHBM di KPH Bandung Utara

\begin{tabular}{llcc}
\hline & Stakeholder & Nilai Kepentingan & Nilai Pengaruh \\
\hline 1 & Perum Perhutani Unit III & 4,67 & 4,56 \\
2 & Dinas Kehutanan & 2,87 & 2,89 \\
3 & Pemerintah Kabupaten & 2,87 & 3,13 \\
4 & Pemerintah Kecamatan & 2,93 & 3,44 \\
5 & Pemerintah Desa & 4,27 & 3,84 \\
6 & LSM & 4,13 & 3,18 \\
7 & BKSDA & 1,87 & 1,82 \\
8 & Masyarakat (KTH) & 4,67 & 3,87 \\
9 & Pengurus LMDH & 4,80 & 4,13 \\
10 & Tokoh Masyarakat & 4,13 & 3,71 \\
11 & BP3K & 1,73 & 1,98 \\
12 & Perguruan Tinggi & 3,00 & 2,51 \\
13 & RPH & 4,60 & 4,04 \\
14 & Mandor & 4,60 & 4,09 \\
15 & Investor & 4,60 & 3,33 \\
\hline
\end{tabular}

Pemetaan dilakukan untuk mengetahui peran masing-masing stakeholder dalam sistem PHBM di KPH Bandung Utara. Terdapat empat kuadran dalam melakukan analisis stakeholder, yaitu kuadran A (subject), kuadran B (player), kuadran C (by stander),

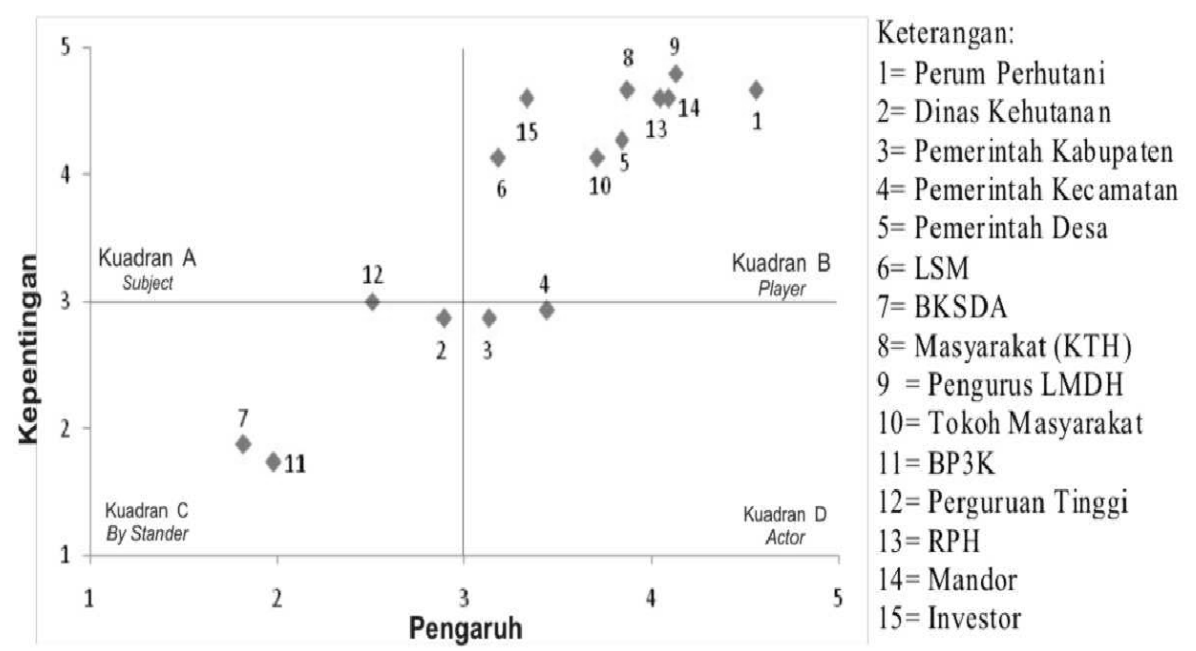

Gambar 2 Pemetaan masing-masing stakeholder sistem PHBM di KPH Bandung Utara 
dan kuadran D (actor). Analisis stakeholder melalui pemetaan actor grid dapat dilihat pada Gambar 2.

Pelaksanaan PHBM di KPH Bandung Utara dilakukan oleh berbagai aktor. Dalam pelaksanaan PHBM aktor-aktor tersebut saling bekerja sama dan bersinergi. Ostrom (1990) dalam Rudiyanto (2011) menyatakan bahwa dalam menganalisis hubungan antar aktor pada sistem kelembagaan, perlu dibedakan berdasarkan tingkatannya (level). Pertama adalah level konstitusi (constitutional), yaitu lembaga yang berperan dalam menyusun aturan main untuk level collective choice. Kedua adalah level pilihan kolektif (collective choice), yaitu lembaga yang berperan dalam menyusun peraturan untuk dilaksanakan oleh lembaga operasional. Ketiga adalah lembaga operasional (operational), yaitu lembaga yang secara langsung melaksanakan kebijakan di lapangan.

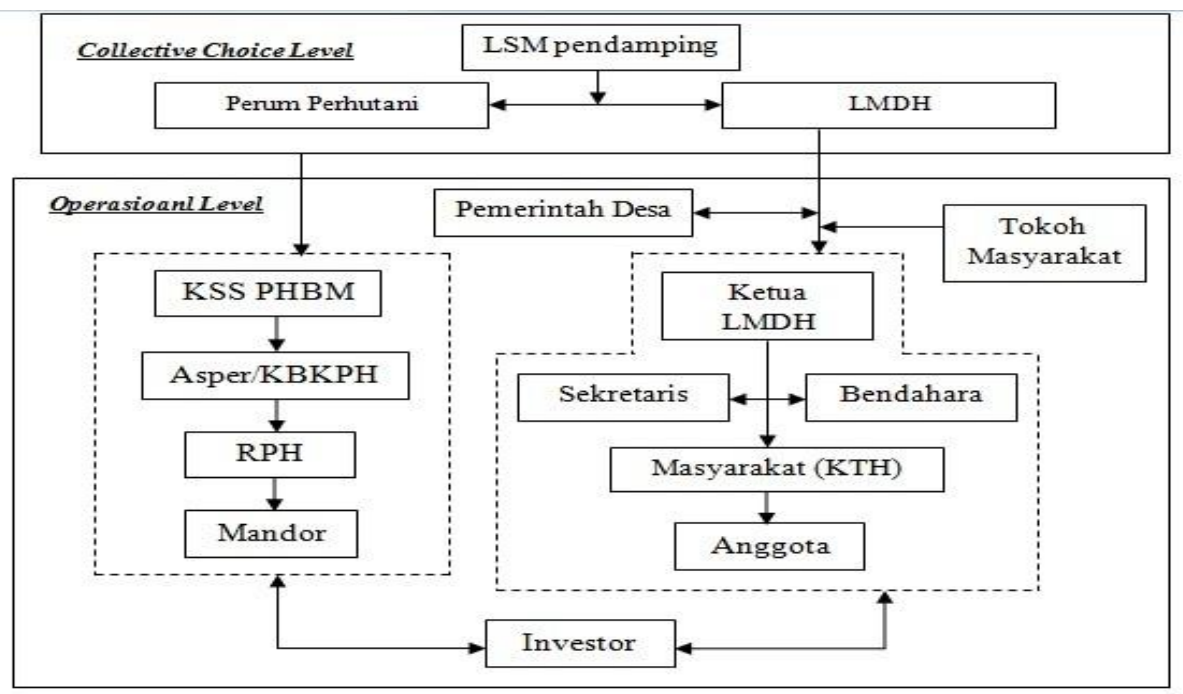

Gambar 3 Keterkaitan antara stakeholder

Keterangan:

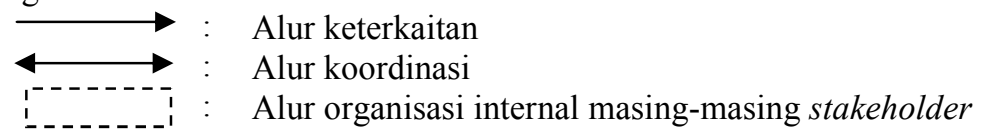

Hasil analisis pada dokumen masing-masing lembaga dan wawancara dengan key person menunjukkan bahwa pada level penentu kebijakan (collective choice) stakeholder yang berperan adalah Perum Perhutani, LSM pendamping dan LMDH. Adapun stakeholder yang berperan pada level operasional adalah KSS PHBM, Asper/KBKPH, RPH, Mandor, Pengurus LMDH (Ketua, Sekretaris, Bendahara, Masyarakat Kelompok Tani Hutan dan Anggota), Pemerintah Desa, Tokoh Masyarakat, dan Investor. Struktur keterkaitan antara stakeholder dijabarkan pada Gambar 3.

Berdasarkan Gambar 3, masing-masing aktor dalam pelaksanaan PHBM berinteraksi satu sama lain sesuai dengan peranannya. Melalui KSS PHBM Perhutani saling berkoordinasi dengan asper/KBKPH, RPH, dan Mandor. Sedangkan LMDH selain berkoordinasi secara internal dalam kelembagaannya, LMDH juga saling berkoordinasi dengan Pemerintah Desa dan Tokoh Masyarakat. Selain itu, LSM Pendamping menjadi fasilitator Perhutani dalam pendampingan administrasi LMDH dan pelaksanaan PHBM. Masing-masing pihak saling bekerjasama agar tujuan dari program PHBM dapat tercapai. 


\section{Indikator Prasyarat Kelembagaan PHBM}

Analisis prasyarat kelembagaan PHBM menunjukkan bahwa dari 59 LMDH yang berada di KPH Bandung Utara 47 LMDH termasuk pada kategori aktif, $12 \mathrm{LMDH}$ dorman dan tidak terdapat LMDH yang tergolong collapse. Analisis efektivitas kelembagaan PHBM dilihat dengan beberapa indikator prasyarat kelembagaan yaitu struktur organisasi, pembagian kerja, peraturan, tujuan organisasi, program kerja, transparasi dan akuntabilitas, partisipasi dan pengambilan keputusan, pengawasan, sanksi, skema evaluasi serta mekanisme petanggung jawaban. Selain terdapat aturan formal, dalam LMDH juga terdapat boundary rule. Boundary rule merupakan aturan yang secara spesifik mengatur bagaimana seseorang dapat masuk atau keluar dari posisi anggota atau pengurus LMDH. Pada AD/ART LMDH, syarat-syarat untuk menjadi anggota adalah setiap MDH yang ingin menjadi anggota harus mengajukan permohonan serta persyaratan secara tertulis mengenai kesediaan mengikuti dan menjalankan AD/ART serta pedoman-pedoman pokok lainnya kepada pengurus. Masa keanggotaan LMDH dihitung mulai dari ketika masyarakat mendaftarkan diri dan habis masa keanggotaannya. Masa habis keanggotaan dikarenakan meninggal dunia, atas permintaan sendiri dan diberhentiakn/dipecat. Sedangkan pergantian pengurus LMDH dilakukan selama lima tahun terhitung sejak pelantikan/serah terima jabatan dan pengurus demisioner, di mana penentuan berdasarkan hasil musyawarah bersama.

\section{Dampak PHBM terhadap Kondisi Ekonomi dan Ekologi Hutan}

Berdasarkan hasil penelitian ini, PHBM mampu meningkatkan pendapatan masyarakat secara signifikan. Kegiatan PHBM menyumbang pendapatan masyarakat berkisar antara $52 \%$ hingga $85 \%$ dari total pendapatan masyarakat desa hutan di KPH Bandung Utara. Secara keseluruhan kontribusi PHBM terhadap pendapatan terhadap masyarakat desa hutan dapat dilihat pada Tabel 2. Berdasarkan Tabel 2 tersebut diatas, terlihat bahwa PHBM mempunyai kontribusi positif terhadap penerimaan masyarakat desa hutan di KPH Bandung Utara. Pada LMDH Cipada PHBM berkontribusi 73,64\% terhadap total penerimaan masyarakat anggota LMDH, sedangkan pada LMDH Kertawangi PHBM berkontribusi sebesar 52,43\% dari total penerimaan. Pada LMDH Cihideung dan Cikole kontribusi PHBM terhadap penerimaan masyarakat adalah sebesar 84,95\% dan 83,60\%. Penerimaan masyarakat di LMDH Cihideung jauh lebih tinggi dibandingkan LMDH lainnya yakni mencapai Rp 3,2 milyar. Hal itu disebabkan jenis usaha tani yang dikembangkan LMDH Cihideung merupakan jenis usaha yang lebih menguntungkan seperti sayur-sayuran dan peternakan, juga kegiatan masyarakat anggota LMDH Cihideung lebih beragam. Kontribusi penerimaan dari kegiatan LMDH di Cihideung adalah sebesar 84,95\%.

Tabel 2 Kontribusi PHBM terhadap penerimaan masyarakat desa hutan

\begin{tabular}{llcc}
\hline Lokasi LMDH & Sumber Penerimaan & Nilai Penerimaan (Rp) & $\%$ \\
\hline LMDH Cipada & Penerimaan PHBM & 1.851 .870 .000 & $73,64 \%$ \\
& Penerimaan Non PHBM & 663.000 .000 & $26,36 \%$ \\
& Total & 2.514 .870 .000 & \\
\hline LMDH Kertawangi & Penerimaan PHBM & 1.436 .070 .000 & $52,43 \%$ \\
& Penerimaan Non PHBM & 1.303 .200 .000 & $47,57 \%$ \\
& Total & 2.739 .270 .000 & \\
\hline LMDH Cihideung & Penerimaan PHBM & 3.196 .920 .000 & $84,95 \%$ \\
& Penerimaan Non PHBM (Rp.) & 566.400 .000 & $15,05 \%$ \\
& Total & 3.763 .320 .000 & \\
\hline LMDH Cikole & Penerimaan PHBM (Rp.) & 2.019 .800 .000 & $83,60 \%$ \\
& Penerimaan Non PHBM (Rp.) & 396.200 .000 & $16,40 \%$ \\
& Total & 2.416 .000 .000 & \\
\hline
\end{tabular}

Penerapan sistem PHBM selain berdampak terhadap ekonomi masyarakat desa hutan juga berdampak terhadap ekologi hutan. Hasil analisis IPA (Gambar 4 dan 5) menunjukkan 
bahwa pengaruh sistem PHBM bagi masyarakat telah memenuhi indikator kepuasan masyarakat. Hal ini ditunjukkan oleh pemetaan tingkat ketersediaan sumberdaya hutan dan tingkat kepentingan sumberdaya hutan bagi masyarakat seluruhnya berada pada Kuadran II, yaitu memiliki tingkat ketersediaan dan kepentingan yang tinggi.

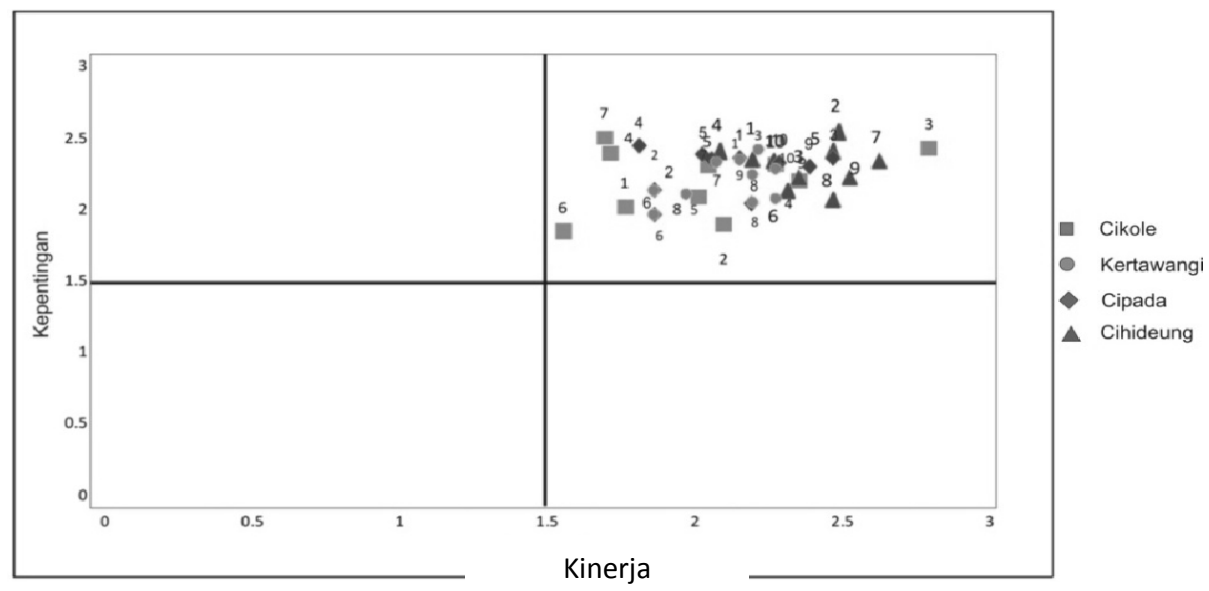

Keterangan:

1. Ketersediaan sumberdaya hutan

2. Luas pengelolaan hutan kurang dari $0,5 \mathrm{Ha}$

6. Banyaknya sumberdaya hutan yang dijual

3. Upaya perluasan lahan pengelolaan

7. Menggunakan tambahan modal

4. Mencukupi seluruh kebutuhan rumah tangga

8. Menggunakan tenaga kerja upahan

5. Menjual hasil sumberdaya hutan

9. Menggunakan tenaga kerja dari keluarga

10. Keberlanjutan usaha tani

Gambar 4 Grafik kartesius IPA persepsi masyarakat terhadap PHBM dan dampak ekonomi bagi masyarakat desa hutan

Masyarakat merasa pelaksanaan sistem PHBM di KPH Bandung Utara sudah dilakukan dengan tepat, sehingga memberikan dampak positif terhadap kondisi ekonomi dan ekologi hutan.

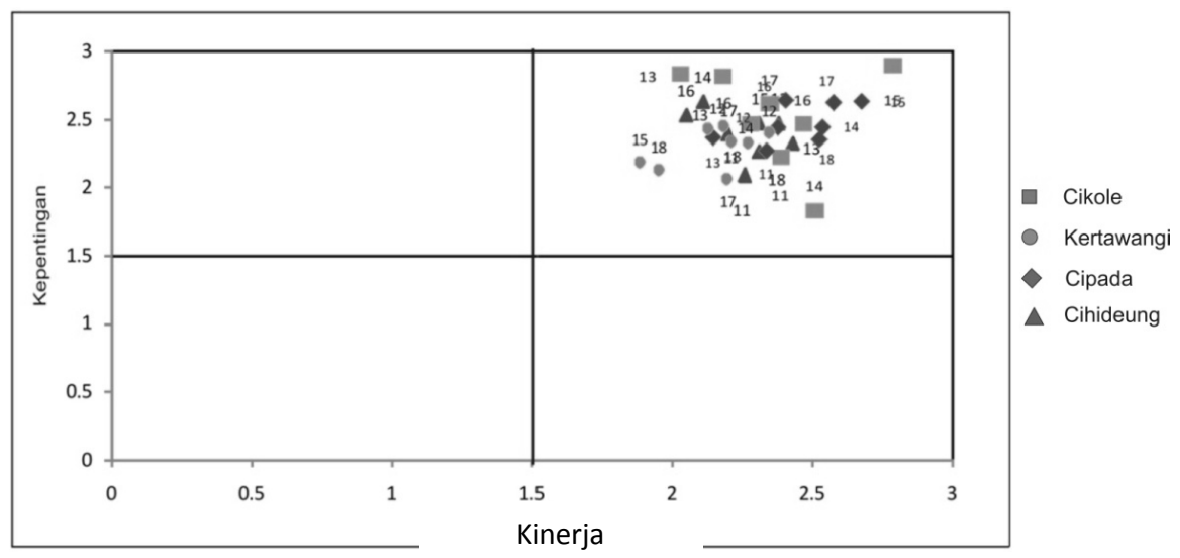

Keterangan:

11. Bencana alam $/$ krisis ekologi

15. Pengaruh PHBM terhadap hidrologi

12. Pengaruh krisi ekologi terhadap perubahan mata pencaharian

13. Pengaruh krisis ekologi terhadap hilangnya mata 17. Pengaruh PHBM terhadap jumlah pohon pencaharian

14. Pengaruh PHBM terhadap tutupan lahan

18. Pengaruh PHBM terhadap ekonomi rumahtangga dilihat dari sisi ekologi

Gambar 5 Grafik kartesius IPA persepsi masyarakat terhadap PHBM dan dampak ekolagi hutan 
Manfaat lain dari pelaksanaan sistem PHBM juga dapat dirasakan oleh masyarakat secara umum, diantaranya berupa kondisi hidrologi yang lebih baik sehingga kebutuhan masyarakat terhadap air bersih tetap terpenuhi dengan baik.

\section{SIMPULAN DAN SARAN}

\section{Simpulan}

Simpulan dari hasil penelitian ini adalah sebagai berikut:

1. Hasil penelitian menunjukkan bahwa kelembagaan PHBM di KPH Bandung Utara sudah cukup efektif dalam mencapai tujuannya baik dalam peningkatan pendapatan masyarakat maupun menjaga kondisi ekologi.

2. Penerapan sistem PHBM di KPH Bandung Utara berdampak terhadap peningkatan kondisi ekonomi rumah tangga dan perbaikan kondisi ekologi hutan. Kegiatan PHBM menyumbang pendapatan masyarakat berkisar antara 52\% hingga $85 \%$ dari total pendapatan masyarakat desa hutan di KPH Bandung Utara. Adapun dampak ekologi dari pelaksanaan PHBM yaitu bertambahnya tutupan lahan, semakin baiknya kondisi hidrologi, berkurangnya gangguan hutan, serta bertambahnya jumlah pohon pada kawasan hutan.

3. Kelembagaan LMDH dapat direplikasi pada kawasan hutan lindung lainnya dengan payung hukum yang jelas dan pelibatan stakeholder yang lebih luas.

\section{Saran}

Berdasarkan hasil penelitian, saran yang dapat peneliti ajukan diantaranya adalah:

1. Peran masyarakat dalam pengelolaan sumberdaya hutan lebih dioptimalkan lagi melalui pembinaan dan pemberdayaan LMDH, baik dari sisi modal, SDM maupun kelembagaan.

2. Pengawasan terhadap penggarapan lahan hutan lebih ditingkatkan dan dipertegas, sehingga lahan yang telah dibuka benar-benar digarap dengan bertanggungjawab.

3. Peran BKSDA dan BP3K lebih ditingkatkan lagi dalam pelaksanaan PHBM melalui koordinasi dan pembagian tugas dengan stakeholder lainnya, terutama dengan LMDH.

4. LMDH Kertawangi dapat lebih meningkatkan aktivitas pengelolaan hutan melalui sistem PHBM, misalnya melalui peningkatan potensi wisata dan penanaman HMT. Harapannya HMT yang dihasilkan selain dapat memenuhi kepentingan ternak pribadi juga dapat dijual.

5. Perlu dilakukan penelitian selanjutnya yang lebih mendalam mengenai hubungan dampak ekologi dari adanya sistem PHBM terhadap kondisi sosial-ekonomi masyarakat dan juga penerapan kelembagaan PHBM pada kawasan hutan lindung lainnya.

\section{DAFTAR PUSTAKA}

Creswell JW. 2003. Research Design Qualitative and Quantitative Approaches alih bahasa Angkatan III dan IV KIK-UI. Jakarta (ID): KIK Press.

Heryawan A. 2011. Pengelolaan Hutan di Jawa Barat [internet]. Tersedia pada: http://www.neraca.co.id/harian/article/3037/Pengelolaan Hutan di Jabar Harus Ditingkatkan.

Husen U. 1999. Metodologi Penelitian: Aplikasi Pemasaran. Jakarta (ID): Gramedia.

[Keputusan Presiden RI] 1990. Keputusan Presiden RI No 32/1990 Tentang Pengelolaan Kawasan Lindung

Ostrom E. 1990. Governing of the common. The Evolution of Institutions for Collective Action. Cambridge University Press.

Ostrom, E. 2003. How Type of Goods and Property Rights Jointly Affect Collective action. Journal of Theoritical Politics Vol. 15 (3). 
[Perda]. 2011. Peraturan Daerah Jawa Barat No. 10 Tahun 2011 Tentang Perlindungan dan Pemberdayaan Masyarakat LMDH Hutan. Bandung (ID): Setda Pemda Jabar.

[Perum Perhutani]. 2001. Keputusan Direksi No. 136/KPTS/DIR/2001 tentang Pedoman Pengelolaan Sumberdaya Hutan Bersama Masyarakat. Bandung (ID): Perum Perhutani Unit III Jabar

[Perum Perhutani Unit III]. 2012. Data Perum Perhutani Unit III BBKSDA Jabar. Bandung (ID): Perum Perhutani Unit III Jabar.

Rudiyanto BY. 2011. Analisis Kelembagaan Dan Biaya Transaksi Dalam Pengelolaan Sea Farming Di Pulau Panggang Kabupaten Administrasi Kepulauan Seribu [tesis]. Bogor (ID): Institut Pertanian Bogor.

Schlager, E and E, Ostrom. 2005. Property-Rights Regimes and Natural resources: A Concept Analys. Land Economic 68 (3).

[Surat Keputusan].2003. Surat Keputusan (SK) Menteri Kehutanan No. 195/Kpts-II/2003 tentang Penunjukan Kawasan Hutan di wilayah Jawa Barat

Sugiyono, (2008). Metode Penelitian Kunatitatif Kualitatif dan R\&D. Bandung Alfabeta

Lampiran 1 Kerangka pemikiran penelitian

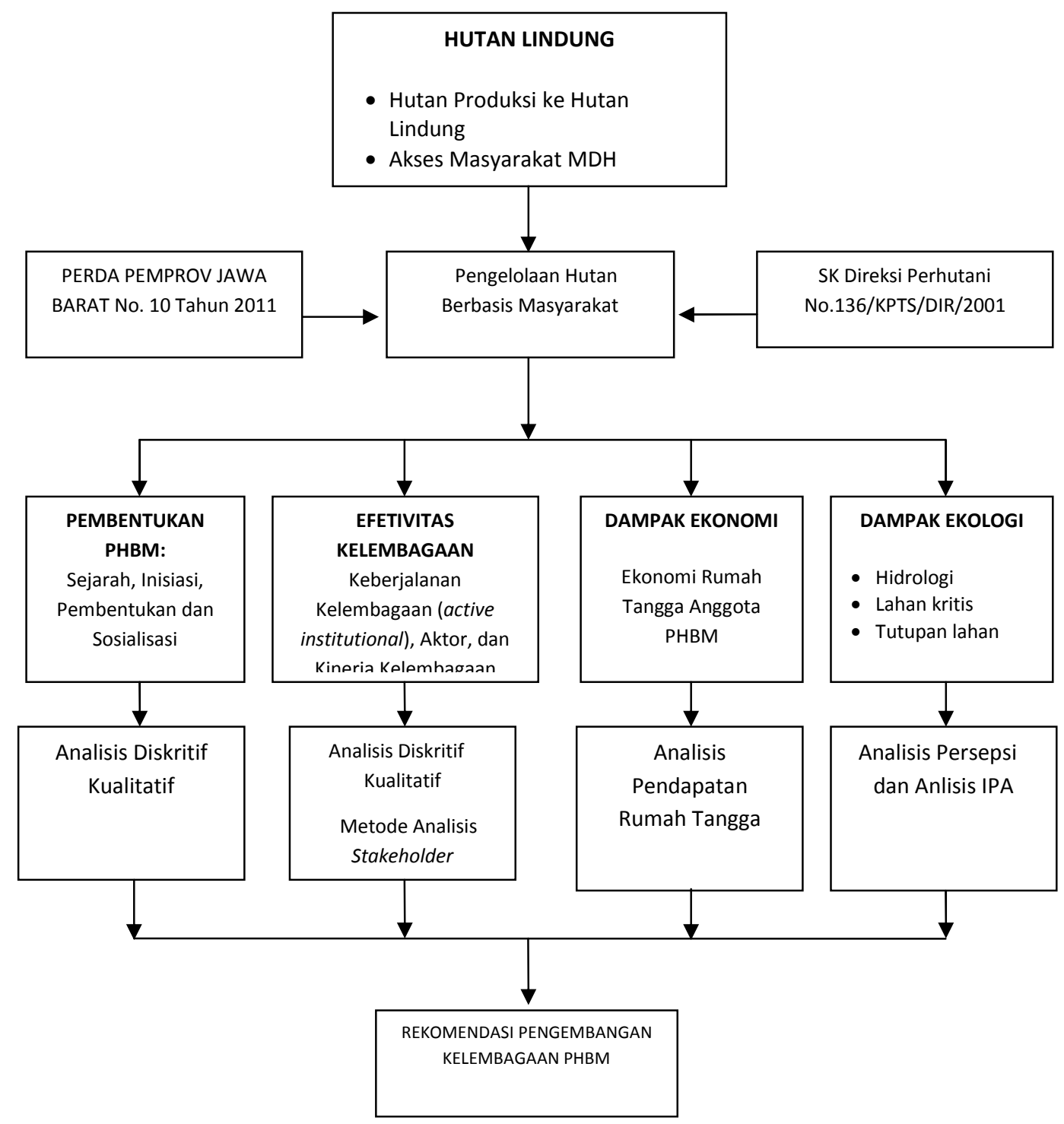


Lampiran 2 Peta lokasi penelitian

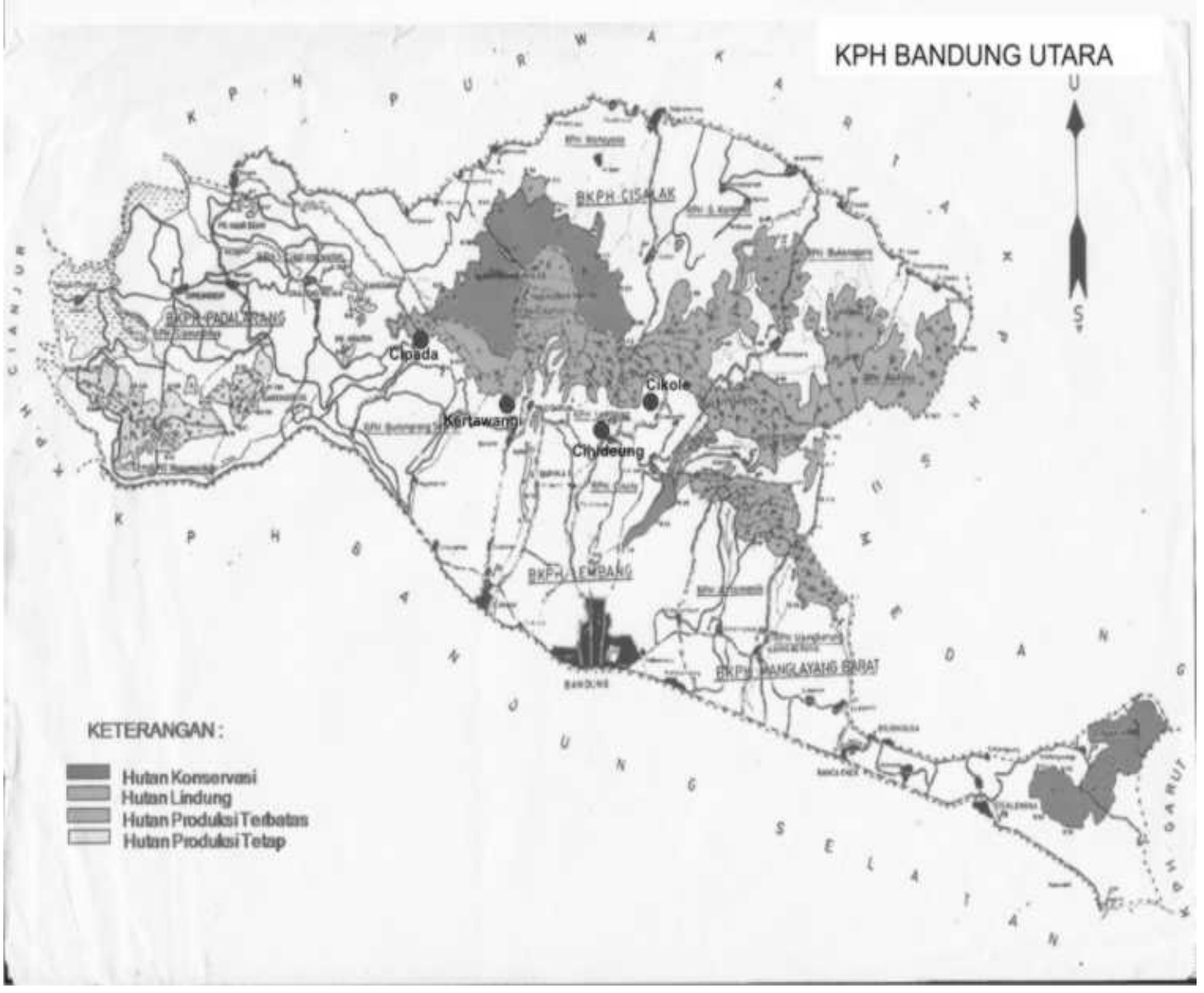

